\title{
5 Research Square

\section{Tranexamic Acid Administration for the Prevention of Blood Loss After Vaginal Delivery in a High-Risk Pregnancy: A Double-blind Randomized Controlled Trial}

Chro Sharef Hasan

Maternity Teaching Hospital, Directorate of Health, Erbil city

Shahla Kareem Alalaf ( $\sim$ shahla_alaf@yahoo.com )

Hawler Medical University, College of medicine https://orcid.org/0000-0003-1259-0338

Sazgar Abdulla Khoshnaw

Maternity Teaching Hospital, Directorate of Health, Erbil city

\section{Research Article}

Keywords: High-risk pregnancy, Oxytocin, Postpartum hemorrhage, Third stage labor, Tranexamic acid

Posted Date: February 24th, 2021

DOl: https://doi.org/10.21203/rs.3.rs-216447/v1

License: (c) (i) This work is licensed under a Creative Commons Attribution 4.0 International License.

Read Full License 


\section{Abstract}

Purpose: The purpose of this study was to examine the effectiveness of tranexamic acid administration for the prevention of postpartum hemorrhage in women with high-risk pregnancies. Tranexamic acid, with the recommended oxytocin, was administered in the third stage of labor to reduce vaginal blood loss and prevent postpartum hemorrhage.

Methods: A double-blind randomized placebo-controlled trial with two parallel groups was conducted in women scheduled to undergo vaginal delivery at the Maternity Teaching Hospital, Erbil City, Kurdistan region, Iraq. The women were randomly assigned to receive tranexamic acid (97 women) or placebo (99 women) with oxytocin immediately after fetal delivery in the third stage of labor. We measured vaginal blood loss from fetal to placental delivery and the time from fetal to placental delivery.

Results: The mean blood loss in the oxytocin alone group (group 1) was significantly higher than that in the tranexamic and oxytocin group (group 2). The incidence of postpartum hemorrhage (blood loss of $\geq 500 \mathrm{~mL}$ ) and blood loss of $\geq 250 \mathrm{~mL}$ was significantly higher in group I than in group 2 . The length of the third stage of labor was significantly longer in group 1 than in group 2 .

Conclusions: In the women who delivered vaginally and had risk factors of postpartum hemorrhage, the incidence rates of the primary outcome of postpartum hemorrhage and blood loss of $<250 \mathrm{~mL}$, and the time to placental delivery were significantly lower in the women who received tranexamic acid with active management of third stage labor than in those who received placebo.

Trial registration number: ClinicalTrials.gov ID: NCT04201951, December 17, 2019

\section{Introduction}

Postpartum hemorrhage (PPH) and its complications are the main causes of maternal mortality and morbidity, predominantly in developing countries, which results in direct maternal death in up to $25 \%$ of cases $[1,2]$.

The prevalence rate of $\mathrm{PPH}$ in the published literature varies widely from $3-15 \%$ of vaginal and cesarean deliveries $[3,4]$. The World Health Organization's recommendations for active management of the third stage of labor (AMTSL), 2012, recommends the use of uterotonics, preferably oxytocin, for the prevention of PPH during the third stage of labor in all deliveries, including any women with risk factors of PPH [5]. $\mathrm{PPH}$ can be prevented by identifying women with the highest risk of $\mathrm{PPH}$, allowing for measures to be taken for AMTSL, the presence of experienced clinicians, and immediate access to resources such as oxytocin infusion and tranexamic acid (TA). Numerous studies have identified the individual risk factors of $\mathrm{PPH}[6]$.

TA is a synthetic derivative of the amino acid lysine, which exerts its antifibrinolytic effect and can improve the hemostatic mechanism in patients with bleeding [7]. An updated systematic review and 
meta-analysis to evaluate the safety and effectiveness of TA prior to cesarean delivery supported the evidence of a beneficial effect of TA in reducing blood loss and the need for blood transfusion in pregnant women undergoing cesarean section [8].

Regarding the effect of TA as a management medication for $\mathrm{PPH}$, the currently available information suggests that the use of TA in patients with PPH would reduce the use of blood products, the need for surgical intervention, and possibly, blood loss from PPH after vaginal delivery and CS [8, 9]. A Cochrane systematic review also concluded that TA reduces blood loss after vaginal and cesarean deliveries [10].

Evidence shows that management of third stage of labor can directly affect important maternal outcomes such as blood loss, the need for manual removal of the placenta, and postpartum bleeding [11]. Blood loss of up to $500 \mathrm{~mL}$ in healthy women after vaginal delivery does not lead to negative maternal consequences; however, uncontrolled blood loss of $>500 \mathrm{~mL}$ can be fatal [12].

The use of TA as a prophylactic in the third stage of labor results in a reduction of blood loss. However, significant differences in blood loss might not always convey a parallel clinical significance; for instance, in women with severe anemia or cardiovascular diseases, blood loss of as little as $200 \mathrm{~mL}$ during delivery might be life-threatening. To lower the incidence rate of major morbidities and mortality due to PPH, it is vital to reduce blood loss in vaginal deliveries [13].

Studies on the use of TA in the third stage of labor combined with AMTSL to decrease blood loss and prevent PPH are controversial in their methodology, as some were conducted in women with low risk of $\mathrm{PPH}[14,15]$ and differed in their time of TA application in relation to delivery and the mode of receiving oxytocin $[15,16]$, or the studies included both participants who delivered by CS and those who had vaginal deliveries $[17,18]$.

This study was conducted in women with significant risk factors of PPH. TA was administered early during the third stage of labor with the recommended oxytocin as components of AMTSL for reducing vaginal blood loss and preventing PPH. Furthermore, we propose that adding TA as a component of AMTSL could decrease the time to placental delivery.

\section{Methods}

Design and study setting

A double-blind randomized placebo-controlled trial with two parallel groups was conducted in women scheduled to undergo a vaginal delivery at the Maternity Teaching Hospital, Erbil City, Kurdistan region, Iraq, between February 1,2020, and October 10,2020. The women were randomly assigned to receive TA or placebo immediately, along with the administration of a uterotonic agent, after fetal delivery in the third stage of labor, and their data were collected. Blood loss was measured during two periods, from fetal to placental delivery and from placental delivery to 2 hours after. 
Eligible participants were women aged $\geq 18$ years who had a singleton pregnancy at $\geq 35$ weeks of gestation, grand multiparity, a twin pregnancy, polyhydramnios, a previous history of $\mathrm{PPH}$, a previous history of cesarean section, suspected macrocosmic fetus, prolonged labor, HELLP (hemolysis, elevated liver enzymes, and low platelets) syndrome, been receiving low-molecular-weight heparin and aspirin during pregnancy, an intention to deliver vaginally, and agreed to participate.

Patients with intrauterine fetal death, history of thromboembolic disease, current, or previous history of heart disease, renal and liver disorders, history of seizure or epilepsy, placenta previa, and placental abruption or refusal to participate were excluded from the trial. An obstetrician (one of the authors) provided the women with information about the trial during early labor when the obstetrician considered that vaginal delivery was likely ( $\geq 4 \mathrm{~cm}$ of cervical dilation). The women confirmed participation at the labor ward and provided written informed consent.

\section{Randomization and procedures}

Eligible women were randomly assigned in a 1:1 ratio to receive $1 \mathrm{~g}$ of TA or placebo (glucose water) administered intravenously. A computer-generated randomization code list was created using the program accessible at www.randomization.com. Two blocks of randomly varied sizes were used for the two arms. An independent statistician generated the randomization numbers. TA and placebo were prepared at a single site and by the same person (an independent pharmacist in the labor ward pharmacy). They were numbered and labeled in infusion bags containing a 30-cc syringes labeled as bag A (experimental group), containing $1 \mathrm{~g} / 10 \mathrm{~mL}$ tranexamic acid diluted with $20 \mathrm{~mL}$ of $5 \%$ glucose water, and bag B (placebo group), containing $30 \mathrm{~mL}$ of $5 \%$ glucose water, each with a $30-\mathrm{mL}$ vial of the trial regimens ( $1 \mathrm{~g}$ of TA or normal saline) depending on the randomization number. Neither the investigators nor the participants were aware of the trial-group assignments.

At the end of the delivery, the randomized number of the bag was applied to the questionnaires containing information about the patient and the details of the procedures. A statistician in the College of Medicine of Hawler Medical University independently analyzed the data until the trial was completed and the database was closed. All the participating women, researchers, and data handlers were blinded to the individual allocations throughout the study.

Interventional drug and grouping

The participants in the interventional group received two ampules of $5 \mathrm{~mL}$ TA added to $20 \mathrm{~mL}$ of $5 \%$ glucose water (TRENAXA $500 \mathrm{mg}$, Macleod Pharmaceuticals Ltd., India). The placebo group received 30 $\mathrm{mL}$ of glucose water $5 \%$ [Glucose (B Braun) $50 \mathrm{mg} / \mathrm{mL}$ ] and oxytocin $(5 \mathrm{IU} / \mathrm{mL}, 2 \mathrm{~mL}$; Gland Pharma Limited).

Trial procedure

The intravenous trial regimen was administered slowly (over a period of 60 seconds) immediately after fetal delivery, coinciding with the routine prophylactic intravenous injection of oxytocin and clamping of 
the umbilical cord. All the other aspects of the management of the third stage of labor were the same in the two groups.

The duration of the third stage was measured and recorded in minutes starting from injection of both medications (oxytocin + TA and oxytocin + glucose water) and placental delivery. During the fetal delivery, a sterile disposable pad of known weight was placed beneath the patient's buttocks to collect blood loss and then weighed. Blood loss was measured during two periods, from fetal to placental delivery and from placental delivery to 2 hours after childbirth. Blood soaked gauzes, gowns, sheets, and tampons were all weighed before and after use (when blood soaked), and blood loss was estimated using the formula of Gai et al. [14] as follows: quantity of blood $(\mathrm{mL})=$ (weight of used materials - weight of materials before use)/1.05.

Maternal observations were recorded every 15 minutes in the first hour and every $30 \mathrm{~min}$ in the second hour after delivery, and these data were recorded.

Sample size estimation

The sample size was estimated using the openepi.com computer program. The information entered in the program was based on the results of a pilot study involving 15 women in each study group (oxytocin vs. oxytocin + TA). The mean ( \pm SD) blood loss in group 1 was $176.467 \pm 39.169 \mathrm{~mL}$, and that in group 2 was $162.4 \pm 13.081 \mathrm{~mL}$. The power was set at $90 \%$; and the confidence interval, at $95 \%$. Accordingly, the estimated sample size for the clinical trial was 100 in each group.

Statistical analysis

Data were analyzed using the Statistical Package for Social Sciences (version 25). The Student $t$ test for two independent samples was used to compare two means. Multiple regressions were used where the dependent variables were the amount of blood loss and the duration of the third stage of labor. A p value of $\leq 0.05$ was considered statistically significant.

\section{Results}

A total of 234 women in labor were evaluated for eligibility, of which 38 were excluded because of either not meeting the inclusion criteria or declining to participate in the trial. A total of 196 women were randomized 1:1 into two groups, of whom 97 were allocated to the TA group and 99 were allocated to the placebo group (Fig. 1).

The sample included 196 women. Their mean ( \pm SD) age was $32.0 \pm 6.6$ years, with a median of 32.0 years and range of 19 to 47 years. Around half (45.9\%) of the women were aged 25 to 34 years (Table 1 ). The gestational age was $>38$ weeks in $53.1 \%$ of the women, and only $4.6 \%$ were nulliparous (Table 1 ). 
Table 1

Basic characteristics of the study sample

\begin{tabular}{|c|c|c|}
\hline & $\mathrm{n}$ & $(\%)$ \\
\hline \multicolumn{3}{|l|}{ Age (years) } \\
\hline$<25$ & 32 & $(16.3)$ \\
\hline $25-34$ & 90 & $(45.9)$ \\
\hline$\geq 35$ & 74 & $(37.8)$ \\
\hline Mean $( \pm S D)$ & 32.0 & $( \pm 6.6)$ \\
\hline \multicolumn{3}{|l|}{ Gestational age (weeks) } \\
\hline $35-38$ & 92 & $(46.9)$ \\
\hline$>38$ & 104 & $(53.1)$ \\
\hline \multicolumn{3}{|l|}{ Parity } \\
\hline Nulliparous & 9 & $(4.6)$ \\
\hline Multiparous 1-4 & 112 & $(57.1)$ \\
\hline Grand multiparous $\geq 5$ & 75 & $(38.3)$ \\
\hline Total & 196 & $(100.0)$ \\
\hline
\end{tabular}

The patients in group $1(n=99)$ were given oxytocin alone, while those in group $2(n=97)$ were given TA in addition to oxytocin. The mean blood loss in group $1(354.5 \mathrm{~mL})$ was significantly $(p<0.001)$ higher than that in group $2(284.4 \mathrm{~mL})$, as shown in Table 2. The mean blood loss did not differ significantly among the following factors: previous history of PPH $(p=0.222)$, macrosomic fetus $(p=0.450)$, and previous history of cesarean section $(p=0.358)$, while the amount of blood loss was significantly higher in those with grand multiparity $(p=0.010)$ and no polyhydramnios $(p=0.005$; Table 2$)$. 
Table 2

Differences in mean blood loss among the studied factors

\begin{tabular}{|c|c|c|c|c|}
\hline & $\mathrm{n}$ & Mean blood loss (g) & $( \pm S D)$ & $\mathbf{p}$ \\
\hline \multicolumn{5}{|l|}{ Intervention } \\
\hline Oxytocin & 99 & 354.5 & $( \pm 97.9)$ & $<0.001$ \\
\hline $\mathrm{TA}+$ oxytocin & 97 & 284.4 & $( \pm 105.1)$ & \\
\hline \multicolumn{5}{|c|}{ Pervious history of PPH } \\
\hline Yes & 27 & 338.4 & $( \pm 78.7)$ & 0.222 \\
\hline No & 169 & 316.9 & $( \pm 110.9)$ & \\
\hline \multicolumn{5}{|c|}{ Prolonged labor } \\
\hline Yes & 1 & 250.0 & $( \pm 0.0)$ & NA \\
\hline No & 195 & 320.2 & $( \pm 107.3)$ & \\
\hline \multicolumn{5}{|l|}{ Multiparous } \\
\hline Yes & 75 & 344.6 & $( \pm 104.3)$ & 0.010 \\
\hline No & 121 & 304.5 & $( \pm 106.5)$ & \\
\hline \multicolumn{5}{|c|}{ Polyhydramnios } \\
\hline Yes & 22 & 260.4 & $( \pm 97.6)$ & 0.005 \\
\hline No & 174 & 327.4 & $( \pm 106.2)$ & \\
\hline \multicolumn{5}{|c|}{ Macrosomic fetus } \\
\hline Yes & 21 & 308.4 & $( \pm 66.6)$ & 0.450 \\
\hline No & 175 & 321.2 & $( \pm 111.1)$ & \\
\hline \multicolumn{5}{|c|}{ Previous history of CS } \\
\hline Yes & 76 & 329.3 & $( \pm 126.9)$ & 0.358 \\
\hline No & 120 & 313.8 & $( \pm 92.6)$ & \\
\hline
\end{tabular}

The length of the third stage of labor was significantly $(p<0.001)$ long in group 1 (10.28 minutes) as compared with that in group 2 ( 7.82 minutes). It was significantly $(p=0.001)$ longer in those with grand multiparity ( 9.61 minutes) than in those with no grand multiparity ( 8.73 minutes). Table 3 shows no significant association between the length of the third stage of labor with the following variables: 
previous history of PPH $(p=0.570)$, polyhydramnios $(p=0.137)$, macrosomic fetus $(p=0.771)$, and previous history of cesarean section $(p=0.438)$.

Table 3

Differences in the mean length of the third stage of labor among the studied factors

\begin{tabular}{|llllll|}
\hline & $\mathbf{n}$ & Mean length of the third stage (min) & $( \pm$ SD) & p \\
\hline Intervention & & & & \\
\hline Oxytocin & 99 & 10.28 & $( \pm 1.33)$ & $<0.001$ \\
\hline TA+ oxytocin & 97 & 7.82 & $( \pm 1.54)$ & \\
\hline Pervious history of PPH & & & & \\
\hline Yes & 27 & 9.26 & $( \pm 1.99)$ & 0.570 \\
\hline No & 169 & 9.04 & $( \pm 1.88)$ & \\
\hline Prolonged labor & & & & \\
\hline Yes & 1 & 9.00 & $( \pm 0.0)$ & NA \\
\hline No & 195 & 9.07 & $( \pm 1.90)$ & \\
\hline Grand multiparity & & & $( \pm 1.90)$ & 0.001 \\
\hline Yes & 75 & 9.61 & $( \pm 1.82)$ & \\
\hline No & 121 & 8.73 & $( \pm 1.92)$ & \\
\hline Polyhydramnios & & & $( \pm 1.85)$ & 0.137 \\
\hline Yes & 120 & 9.15 & $( \pm 1.89)$ & \\
\hline No & 22 & 8.50 & & \\
\hline Macrosomic fetus & 174 & 9.14 & & $( \pm 1.89)$ & \\
\hline Yes & & 9.08 & & \\
\hline No & 21 & 8.95 & & \\
\hline Previous history of CS & & & & \\
\hline Yes & 76 & 8.93 & & \\
\hline No & & & & \\
\hline TA: Tranexamic acid, PPH & Postpartum hemorrhage, CS: Cesarean section & & \\
\hline
\end{tabular}

The incidence of PPH was significantly $(p=0.025)$ higher $(13.1 \%)$ in the oxytocin group (group 1$)$ than in the TA group (4.1\%; group 2; Fig. 2). A same pattern can be observed in Fig. 3 where the incidence of 
blood loss of $>250 \mathrm{~mL}$ was $90.9 \%$ in group 1 and $51.5 \%$ in group $2(p<0.001)$.

Table 4 shows that the women in the TA group and those with polyhydramnios had significantly less amount of blood loss ( $p<0.001$ and $p=0.0 .048$, respectively) irrespective of the other factors. The regression coefficient $(B)$ was -62.33 for the TA group and -47.27 for the women with polyhydramnios.

Table 4

Multiple regression analysis with amount of blood loss (grams) as dependent variable

\begin{tabular}{|lllllllll|}
\hline & \multicolumn{2}{l}{$\begin{array}{l}\text { Unstandardized } \\
\text { Coefficients }\end{array}$} & \multicolumn{2}{l}{$\begin{array}{l}\text { Standardized } \\
\text { Coefficient }\end{array}$} & & \multicolumn{3}{l|}{$\begin{array}{l}95.0 \% \text { Confidence } \\
\text { Interval for } B\end{array}$} \\
\hline & B & SE & Beta & t & p & $\begin{array}{l}\text { Lower } \\
\text { Bound }\end{array}$ & $\begin{array}{c}\text { Upper } \\
\text { Bound }\end{array}$ \\
\hline (Constant) & 350.143 & 13.230 & & 26.466 & $<$ & 324.048 & 376.238 \\
\hline $\begin{array}{l}\text { Intervention } \\
\text { tranexamic acid }\end{array}$ & -62.336 & 14.863 & -0.292 & -4.194 & $<$ & -91.652 & -33.020 \\
\hline Grand multiparity & 15.276 & 15.785 & 0.069 & 0.968 & 0.334 & -15.859 & 46.410 \\
\hline Polyhydramnios & -47.277 & 23.715 & -0.140 & -1.994 & 0.048 & -94.053 & -0.502 \\
\hline
\end{tabular}

Regarding the duration of the third stage of labor, Table 5 shows that when TA was administered, the duration of the third stage of labor significantly decreased $(p<0.001 ; B=-2.39)$.

Table 5

Multiple regression analysis with duration of the third stage of labor (minutes) as dependent variable

\begin{tabular}{|llllllll|}
\hline & \multicolumn{2}{l}{$\begin{array}{l}\text { Unstandardized } \\
\text { Coefficients }\end{array}$} & $\begin{array}{l}\text { Standardized } \\
\text { Coefficient }\end{array}$ & $\boldsymbol{t}$ & $\mathbf{p}$ & \multicolumn{2}{c|}{$\begin{array}{l}\text { 95\% Confidence } \\
\text { Interval for } \boldsymbol{B}\end{array}$} \\
\hline & $\mathrm{B}$ & $\begin{array}{c}\text { Standard } \\
\text { Error }\end{array}$ & Beta & & & $\begin{array}{c}\text { Lower } \\
\text { Bound }\end{array}$ & $\begin{array}{c}\text { Upper } \\
\text { Bound }\end{array}$ \\
\hline (Constant) & 10.152 & 0.182 & & 55.820 & $<$ & 9.793 & 10.510 \\
\hline $\begin{array}{l}\text { Intervention } \\
\text { tranexamic acid }\end{array}$ & -2.394 & 0.212 & -0.634 & -11.268 & $<$ & -2.813 & -1.975 \\
\hline Grand multiparity & 0.260 & 0.219 & 0.067 & 1.188 & 0.236 & -0.171 & 0.691 \\
\hline
\end{tabular}

\section{Discussion}

In this clinical trial involving women who delivered vaginally and were at risk of $\mathrm{PPH}$, all those who received prophylactic oxytocin and TA with oxytocin had significantly lower incidence rates of PPH ( $\geq$ $500 \mathrm{~mL}$ ) than those who received placebo (glucose water plus oxytocin). Furthermore, the incidence of vaginal blood loss of $>250 \mathrm{~mL}$ in the third stage of labor was significantly lower the TA group. 
Many previous studies used TA to prevent PPH and confirmed the same finding as in the present study that TA is a complementary component of the management of the third stage of labor for preventing PPH [18-20].

This trial was restricted to pregnant women who had high-risk factors of PPH; we did not include women with lower risks in the routine management of the third stage of labor. Most other previous studies with the same objectives included generally women who delivered, some of whom having risk factors $[4,5,10$, 15-17]. We assumed that women with high-risk factors are more prone to $\mathrm{PPH}$.

The time of the third stage of labor to successfully deliver the placenta in the TA group was surprisingly significantly shorter than that in the routine group. This raises the concern whether TA can be used for this purpose besides decreasing vaginal blood loss after delivery. More trials are needed to confirm this property of TA.

Postpartum blood loss was determined objectively by estimating the amount of blood loss by weighing all soaked diapers and mattresses and weighing any clots. Quantitative methods of measuring obstetric blood loss using gravimetric methods have been shown to be more accurate than visual estimation methods [18].

We did not examine the side effects of TA. However, previous studies found that vomiting or nausea was more frequent in the TA group than in the placebo group, and both features were not reported to be severe $[19,20]$. We also did not examine the risk factor of venous thromboembolism (VTE) associated with the use of TA, as the authors of a double-blind randomized placebo-controlled trial conducted in 20000 women who had delivered and received either TA or placebo with a clinical diagnosis of PPH concluded that adverse events, including VTE, did not differ significantly between the groups [6].

This trial has some limitations. It was not a multicenter trial; thus, its results were limited to the current hospital and could not be generalized to other institutions. This also suggests the need for future studies that include many settings but using the same protocol.

Although we estimated the sample size into two groups of participants according to a pilot study using TA and placebo, still the sample size was small. To generalize the results, a larger sample size, and multicenter research are required.

The trial did not have the power to assess the effect of TA on the incidence rates of severe PPH, although none of the women included lost $\geq 1000 \mathrm{~mL}$ of blood vaginally after delivery in both groups of participants

Another limitation is that we included all risk groups of PPH as one group, while the grand multiparous women and those with polyhydramnios were the two at risk groups that would benefit more from TA administration than the other risk groups. We assumed that if a trial could be conducted in the future with a larger sample size and with each risk group included separately, important data on the effect of TA in each risk group may be obtained.

Page 10/16 
In conclusion, the women with vaginal delivery and risk factors of PPH who received TA at the time of AMTSL had significantly decreased incidence rates of PPH and blood loss of $>250 \mathrm{~mL}$ and time to placental delivery than those who received placebo.

\section{Declarations}

\section{Funding}

This study received no funding support.

\section{Conflicts of interest}

The authors declare that they have no conflict of interest.

\section{Availability of data and materials}

The information provided in this article, including all raw data, are available from the corresponding author on reasonable request to any scientist wishing to use them for non-commercial reasons at a condition that participant

\section{Code availability}

Not applicable

\section{Ethical standards}

The experimental protocol of this study was approved by the ethics committee of the Kurdistan Board of Medical Specialty Research Ethics (No. 1398; October 1, 2019). This study was conducted in accordance with the ethical standards of the institutional review committee of the Maternity Teaching Hospital (Document no. 1/9B; October 22, 2019) and the Code of Ethics of the World Medical Association (Declaration of Helsinki 2013; ClinicalTrials.gov ID: NCT04201951)

\section{Authors' contribution}

CS Hasan: Data collection, Manuscript writing and editing

SK Alalaf: Project development, Manuscript writing

SA Khoshnaw: Manuscript writing and editing, Project development

\section{Consent to participate}

All participants were assured that confidentiality would be maintained and that information obtained from them would be used for research purposes only. All study subjects agreed to participate in the trial 
voluntarily and provided written informed consent which included also approval to publish the data in a journal.

\section{Acknowledgments}

The authors would like to express their gratitude to all the subjects who agreed to participate in this study. The authors would also like to thank Enago (www.enago.com) for the English language review.

\section{References}

1. Lalonde A, Daviss BA, Acosta A, Herschderfer K (2006) Postpartum hemorrhage today: ICM/FIGO initiative 2004-2006. Int J Gynecol Obstet 94:243-253. https://doi.org/10.1016/j.ijgo.2006.04.016.

2. Milman N (2011) Postpartum anemia I: Definition, prevalence, causes, and consequences. Ann Hematol 90:1247-1253. https://doi.org/10.1007/s00277-011-1279-z.

3. Calvert C, Thomas SL, Ronsmans C, Wagner KS, Adler AJ, Filippi V (2012) Identifying regional variation in the prevalence of postpartum haemorrhage: a systematic review and meta-analysis. PLOS ONE 7:e41114. https://doi.org/10.1371/journal.pone.0041114.

4. Kramer MS, Berg C, Abenhaim H, Dahhou M, Rouleau J, Mehrabadi A, Joseph KS (2013) Incidence, risk factors, and temporal trends in severe postpartum haemorrhage. Am J Obstet Gynecol 209:449.e1-e7. https://doi.org/10.1016/j.ajog.2013.07.007.

5. WHO (2014) Active management of the third stage of labour,New WHO recommendations help to focus implementation.

https://www.who.int/reproductivehealth/publications/maternal_perinatal_health/newrecommendations-amtsl/en/. Accessed on 14 Jan 2021.

6. Nyfløt LT, Sandven I, Stray-Pedersen B, Pettersen S, Al-Zirqi I, Rosenberg M, Jacobsen AF, Vangen S (2017) Risk factors for severe postpartum hemorrhage: a case-control study. BMC Pregnancy Childbirth 17:17. https://doi.org/10.1186/s12884-016-1217-0.

7. Mccormack $P$ (2012) Tranexamic acid a review of its use in the treatment of hyperfibrinolysis. Drugs 72:585-617. https://doi.org/10.2165/11209070-000000000-00000.

8. Franchini M, Mengoli C, Cruciani M, Bergamini V, Presti F, Marano G, Pupella S, Vaglio S, Masiello F, Veropalumbo E, Piccinini V, Pati I, Liumbruno GM (2018) Safety and efficacy of tranexamic acid for prevention of obstetric haemorrhage: an updated systematic review and meta-analysis. Blood Transfus 16:329-337. https://doi.org/10.2450/2018.0026-18.

9. WOMAN Trial Collaborators. (2017) Effect of early tranexamic acid administration on mortality, hysterectomy, and other morbidities in women with post-partum haemorrhage (WOMAN): an international, randomised, double-blind, placebo-controlled trial. Lancet 389:2105-2116. https://doi.org/10.1016/S0140-6736(17)30638-4.

10. Novikova N, Hofmeyr GJ, Catherine Cluver C (2015) Tranexamic acid for preventing postpartum haemorrhage. Cochrane Database Syst Rev 2015:1-62. 
https://doi.org/10.1002/14651858.CD007872.pub3.

11. Brucker CM (2001) Management of the third stage of labor: an evidence-based approach. $J$ Midwifery Womens Health 46:381-392. https://doi.org/10.1016/S1526-9523 (01)00192-1.

12. Edwards HM (2018) Aetiology and treatment of severe postpartum haemorrhage. Dan Med J 65:B5444.

13. Li Ch, Gong Y, Dong L, Xie B, Dai Zh (2017) Is prophylactic tranexamic acid administration effective and safe for postpartum hemorrhage prevention? A systematic review and meta-analysis. Medicine 96:1(e5653). https://doi.org/10.1097/MD.0000000000005653.

14. Mirghafourvand M, Mohammad-Alizadeh S, Abbasalizadeh F, Shirdel M (2015) The effect of prophylactic intravenous tranexamic acid on blood loss after vaginal delivery in women at low risk of postpartum haemorrhage: a double-blind randomised controlled trial. Aust N ZJ Obstet Gynaecol 55:53-58. https://doi.org/10.1111/ajo.12262.

15. Yang H, Zheng S, Shi C (2001) Clinical study on the efficacy of tranexamic acid in reducing postpartum blood lose: a randomized, comparative, multicenter trial. Zhonghua Fu Chan Ke Za Zhi 36:590-592.

16. Sujita A, Songthamwat S, Songthamwat M (2018) Effectiveness of tranexamic acid for reducing postpartum blood loss in the first two hours after vaginal delivery: A randomised controlled trial. $J$ Clin Diagn Res 12:QC01-QC04. https://doi.org/10.7860/JCDR/2018/32494.11248.

17. Sentilhes L, Lasocki S, Ducloy-Bouthors AS, Deruelle P, Dreyfus M, Perrotin F, Goffinet F, DeneuxTharaux C (2015) Tranexamic acid for the prevention and treatment of postpartum haemorrhage. $\mathrm{Br}$ J Anaesth 114:576-587. https://doi.org/10.1093/bja/aeu448.

18. Sentilhes L, Daniel V, Deneux-Tharaux C (2020) TRAAP2 - TRAnexamic Acid for preventing postpartum hemorrhage after cesarean delivery: a multicenter randomized, double blind, placebocontrolled trial - a study protocol. BMC Pregnancy and Childbirth 20:63. https://doi.org/10.1186/s12884-019-2718-4.

19. Sentilhes L, Winer N, Azria E, et al (2018) Tranexamic acid for the prevention of blood loss after vaginal delivery. N Engl J Med 379:731-742. https://doi.org/10.1056/NEJMoa1800942.

20. Diab KM, Mohamed RM, Abdelhay AG (2020) The efficacy of intravenous tranexamic acid in reduction of blood loss in women at high risk of postpartum hemorrhage. QJM 113:hcaa056.014. https://doi.org/10.1093/qjmed/hcaa056.014.

\section{Figures}




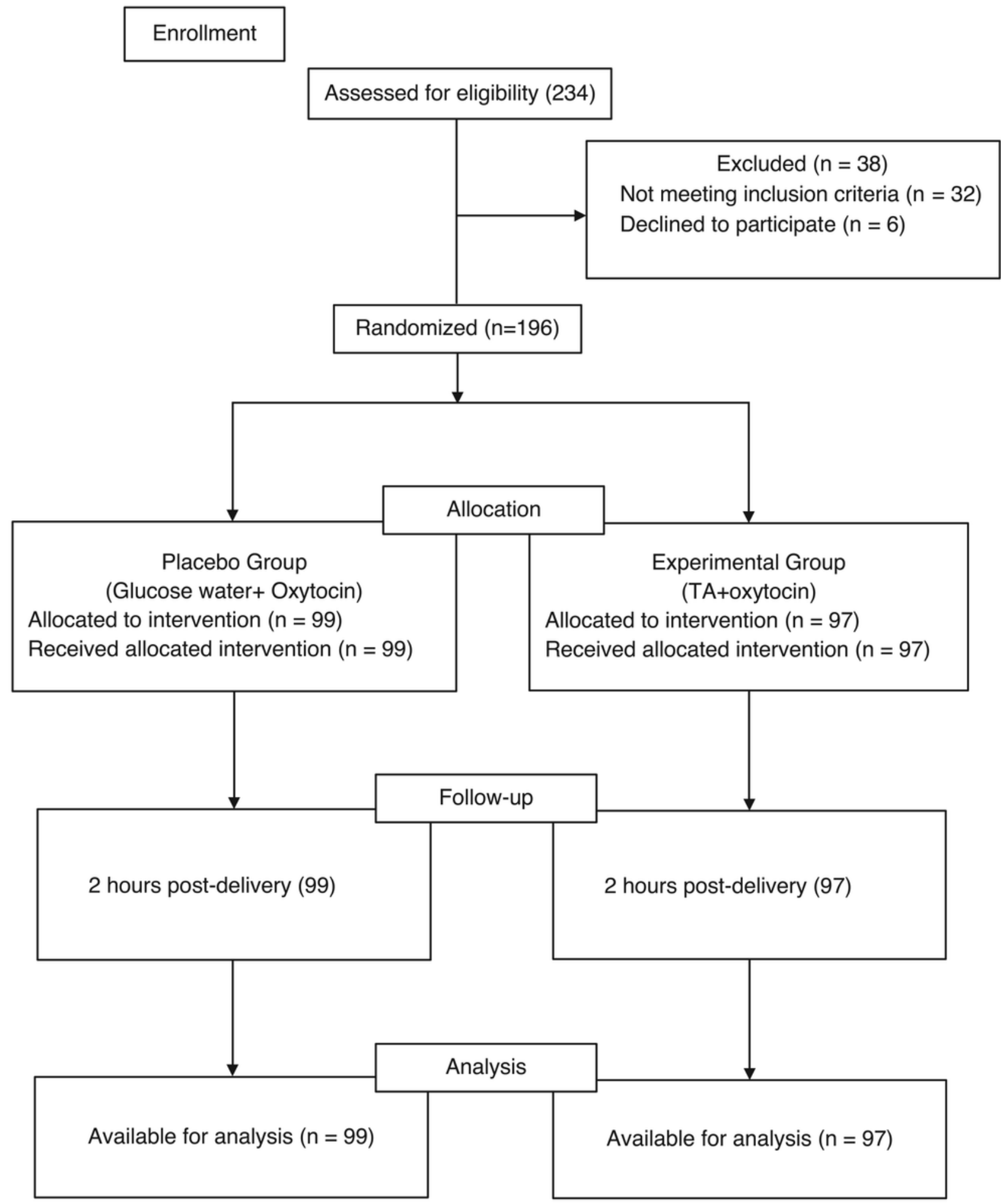

\section{Figure 1}

Flowchart of the study 


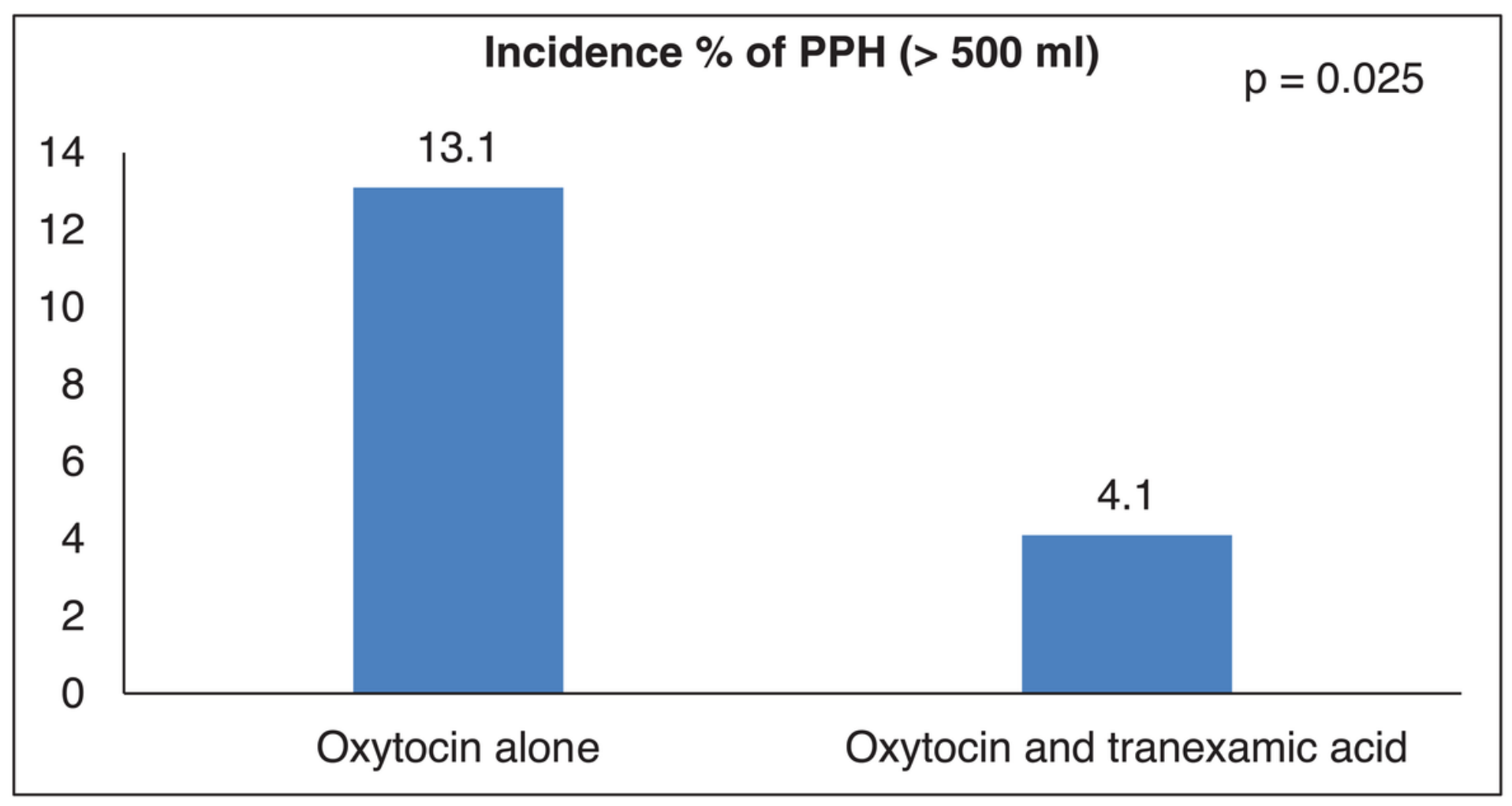

Figure 2

Incidence of postpartum hemorrhage $(>500 \mathrm{~mL})$ in the two study groups

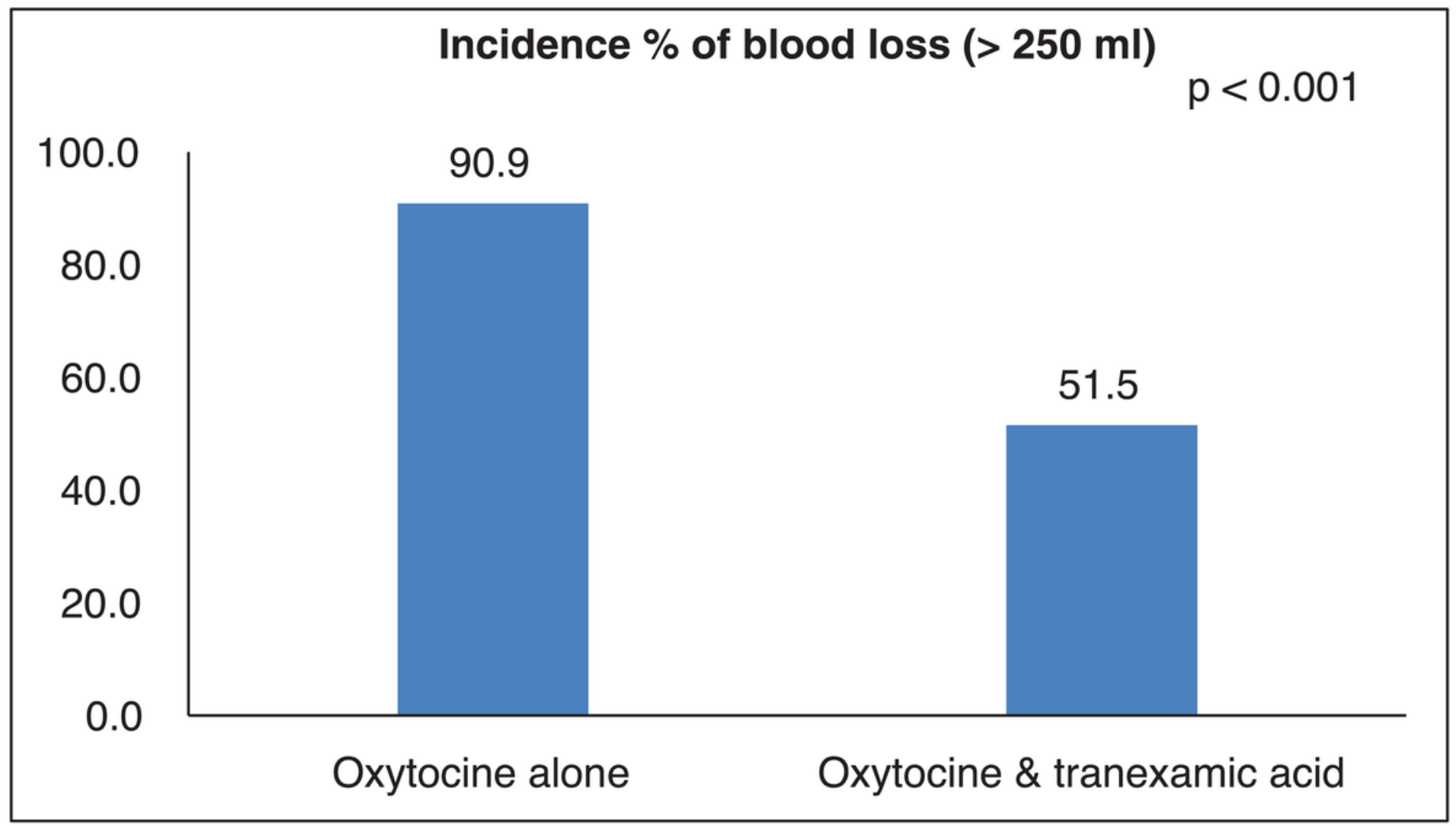

Figure 3 
Incidence of blood loss (>250 mL) in the two study groups 